\section{Association of grip strength with obesity \& cortisol; Possible indicators of biological ageing.}

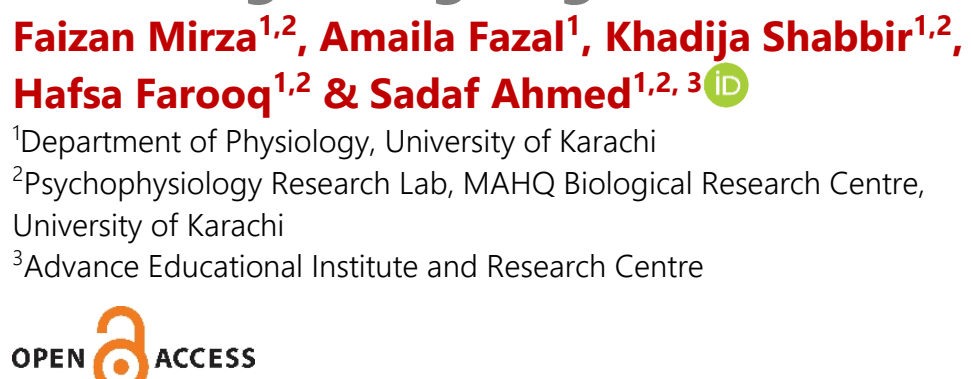

Doi: 10.29052/IJEHSR.v8.i3.2020.145-152

Corresponding Author Email:

fm.faizan.mirza@gmail.com

Received 02/05/2020

Accepted 26/08/2020

First Published 01/09/2020

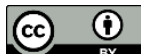

(C) The Author(s). 2020 Open Access This article is distributed under the terms of the Creative Commons Attribution 4.0 International License (http://creativecommons.org/licenses/by/4.0/)

\begin{abstract}
Background: Cortisol has a positive correlation with obesity, which indicates a relation between obesity and cortisol. Furthermore, there are increased chances of demolished muscle strength up to two times with elevated levels of cortisol. Thus, the aim of the study was to assess the impact of increased cortisol levels on the grip strength and to determine that the grip strength is a possible indicator for accelerated biological ageing.

Methodology: This cross-sectional, purposive sampling study was conducted in Karachi, Pakistan. Overall 412 were recruited to participate in the study, the data for age, gender, BMI, grip strength, and cortisol was collected from the participants. The age-wise correlates of hand grip strength were assessed using Multiple linear regression analysis and the mean decline in the grip strength with advancing age is displayed.

Results: The mean grip strength of the overall population was $30.75 \pm 14.35$. It was observed that there was a negative significant correlation between the age and the grip strength $(F=3.57 ; r=-0.27 ; p=0.007)$ i.e. with increasing age a gradual decrease in the grip strength was observed. BMI (Obesity) was also significantly associated with grip strength $(p=0.000)$. Moreover, females were more likely to have weak muscle strength as compared to males $(p=0.000)$. However, no significant association was observed among the grip strength, socioeconomic status \& longevity in any of the studied age groups $(p>0.05)$. While a significant correlation was found between grip strength and obesity as well as between obesity and cortisol.

Conclusion: Thus it can be concluded that obese individuals had increased chances of accelerated biological ageing due to an increase in cortisol, and a weakened grip strength is an indicator of it.
\end{abstract}

\title{
Keywords
}

Ageing, Grip Strength, Cortisol, Obesity, Socioeconomic Status, Longevity.

\section{Check for updates}




\section{Introduction}

Physical fitness is an important parameter for a healthy life, which is generally lost in old age, especially the loss of muscle strength ${ }^{1,2}$. A useful way to estimate physical fitness and physical wellbeing is the determination of grip strength, which is increasingly used as an indicator of overall muscle strength and function ${ }^{3,4}$. Several studies have shown that poor grip strength predicts increased all-cause mortality in older people ${ }^{5,6}$. A study was done on the population of healthy men of middle age, and their grip strength was measured to predict long term death risk, suggests that all the influences that affect muscle function and size earlier in life might be important ${ }^{7}$.

Lower grip strength has also been found associated with higher levels of insulin in fasting, in both cross-sectional and longitudinal studies, this suggests that muscle weakness may precede the development of insulin resistance ${ }^{8,9}$. A drastic rise in cortisol level is also observed postprandial. Increased food intake also causes an increase in cortisol and Adrenocorticotropic hormone (ACTH) level, noted in females who were exposed to visceral obesity. Thus, there is a positive correlation between cortisol and $\mathrm{BMI}$ which indicates a relation between obesity and cortisol ${ }^{10}$. And it is a wellestablished fact that with growing age, grip strength decreases ${ }^{11}$, whereas grip strength is also associated with height and body weight ${ }^{12}$.

Thus, muscle might enhance their volume and along with the bluntness in the production of protein through the vast action of cortisol $^{13}$. Moreover, fluctuations in the volume of the muscles in the elderly have been related to the standard level of cortisol. Chronic stimulation of cortisol has been associated with undesirable outcomes of muscle strength ${ }^{14}$. Increased chances of demolished muscle strength up to two times have been observed with elevated cortisol concentrations ${ }^{15}$.

Under physiological circumstances, ageing causes an increase in cortisol level; this rise in cortisol levels may lead to defects in the systems of the body, and slowly deteriorates the immune system.
Along with the process of ageing, there is a loss of restoration in response to stress, which can cause damage to various organs of the body. On the other hand, ageing also has a blunted effect on regulation and homeostasis of the HPA axis. ACTH adrenal axis is modified according to age with the presence of stress. Increased cortisol level in comparison to the normal level for a longer period of time leads to deterioration of healthy body cells, dampens synaptic activity, decreases neuroplasticity and decreases in the longevity of the cells of the hippocampus. Elevated serum cortisol leads to the destruction of muscles, skeletal system, cognitive functions, increases, android obesity and thus, the quality of life is compromised ${ }^{16}$. Thereby, the aim of the study was to assess the impact of increased cortisol levels \& $\mathrm{BMI}$ on the grip strength and to determine that the grip strength is the possible indicator for accelerated biological ageing.

\section{Methodology}

This study was approved by the Pakistan Medical Association Committee on Ethics (Reference Number: QR/957/NMC/10). This cross-sectional study was carried out in Karachi, Pakistan, from August 2019 till January 2020. Overall 412 were recruited to participate in the study, including both males and females of age groups between 20 to 69 years through purposive sampling. Written informed consent was obtained from each participant, prior to enrollment. The data for age, gender, BMI, grip strength, and cortisol levels was collected from the participants. Subjects having any pathological condition were excluded from this study.

The BMI of the participants was calculated using the formula: $\mathrm{BMI}=\mathrm{kg} / \mathrm{m} 2 \mathrm{BMl}$ and the cutoff values were used as per the World Health Organization (WHO) guidelines. However, to measure the Grip strength electronic hand dynamometer, EH101 was used, and the cortisol levels were measured quantitatively by the immunoassay method.

For assessment of grip strength in association with demographic characteristics, Chi-square test was 
used and $p$-value $<0.05$ was considered significant. The age-wise correlates of hand grip strength were assessed using Multiple linear regression analysis and the mean decline in the grip strength with advancing age is displayed and $p<0.05$ was considered significant.

\section{Result}

It was observed that most of the subjects from either age groups had weak grip strength, 37.39\% of subjects with 20 to 29 years of age, $24.36 \%$ from 30 to 39 years, $19.32 \%$ from 40 to 49 years, $10.92 \%$ from 50 to 59 years, $7.9 \%$ from 60 to 69 years' age group had weak muscle strength $(p<0.018$ ). Although there is a varying trend in the significance values but mostly the subjects had either normal or weak muscle strength.

Table 1: Hand-grip strength by study demographics $(n=412)$

\begin{tabular}{|c|c|c|c|c|c|}
\hline \multirow[t]{2}{*}{ Variables } & \multirow[b]{2}{*}{$\begin{array}{l}\text { Sub- } \\
\text { categories }\end{array}$} & \multicolumn{3}{|c|}{ Grip Strength } & \multirow[b]{2}{*}{ p-value } \\
\hline & & $\begin{array}{c}\text { Weak } \\
(\mathrm{N}=238)\end{array}$ & $\begin{array}{l}\text { Normal } \\
(\mathrm{N}=126)\end{array}$ & $\begin{array}{l}\text { Strong } \\
(\mathrm{N}=48)\end{array}$ & \\
\hline \multirow[t]{2}{*}{ Gender } & Male & 109 & 95 & 35 & \multirow[t]{2}{*}{$0.000^{*}$} \\
\hline & Female & 129 & 31 & 13 & \\
\hline \multirow[t]{5}{*}{ Age (Years) } & 20 to 29 & 89 & 44 & 11 & \multirow[t]{5}{*}{$0.018^{*}$} \\
\hline & 30 to 39 & 58 & 47 & 11 & \\
\hline & 40 to 49 & 46 & 19 & 17 & \\
\hline & 50 to 59 & 26 & 10 & 7 & \\
\hline & 60 to 69 & 19 & 6 & 2 & \\
\hline \multirow{5}{*}{$\begin{array}{l}\text { Socioeconomic } \\
\text { Status (SES) }\end{array}$} & Middle SES & 67 & 27 & 10 & \multirow[t]{5}{*}{0.205} \\
\hline & Upper Middle & 102 & 56 & 22 & \\
\hline & SES & & & & \\
\hline & Low SES & 50 & 35 & 14 & \\
\hline & Upper SES & 7 & 8 & 0 & \\
\hline \multirow[t]{2}{*}{ Marital Status } & Single & 116 & 75 & 14 & \multirow[t]{2}{*}{$0.001^{*}$} \\
\hline & Married & 122 & 51 & 34 & \\
\hline \multirow[t]{3}{*}{ Obesity } & Underweight & 46 & 28 & 7 & \multirow[t]{3}{*}{$0.000^{*}$} \\
\hline & Normal & 168 & 47 & 24 & \\
\hline & Overweight & 24 & 51 & 17 & \\
\hline \multirow[t]{3}{*}{ Cortisol } & Low & 6 & 5 & 0 & \multirow[t]{3}{*}{0.235} \\
\hline & Normal & 217 & 113 & 48 & \\
\hline & High & 15 & 8 & 0 & \\
\hline \multirow[t]{2}{*}{ Longevity } & Present & 167 & 115 & 29 & \multirow[t]{2}{*}{$0.000^{*}$} \\
\hline & Absent & 71 & 11 & 19 & \\
\hline
\end{tabular}

${ }^{*} p<0.05$ is considered statistically significant. 


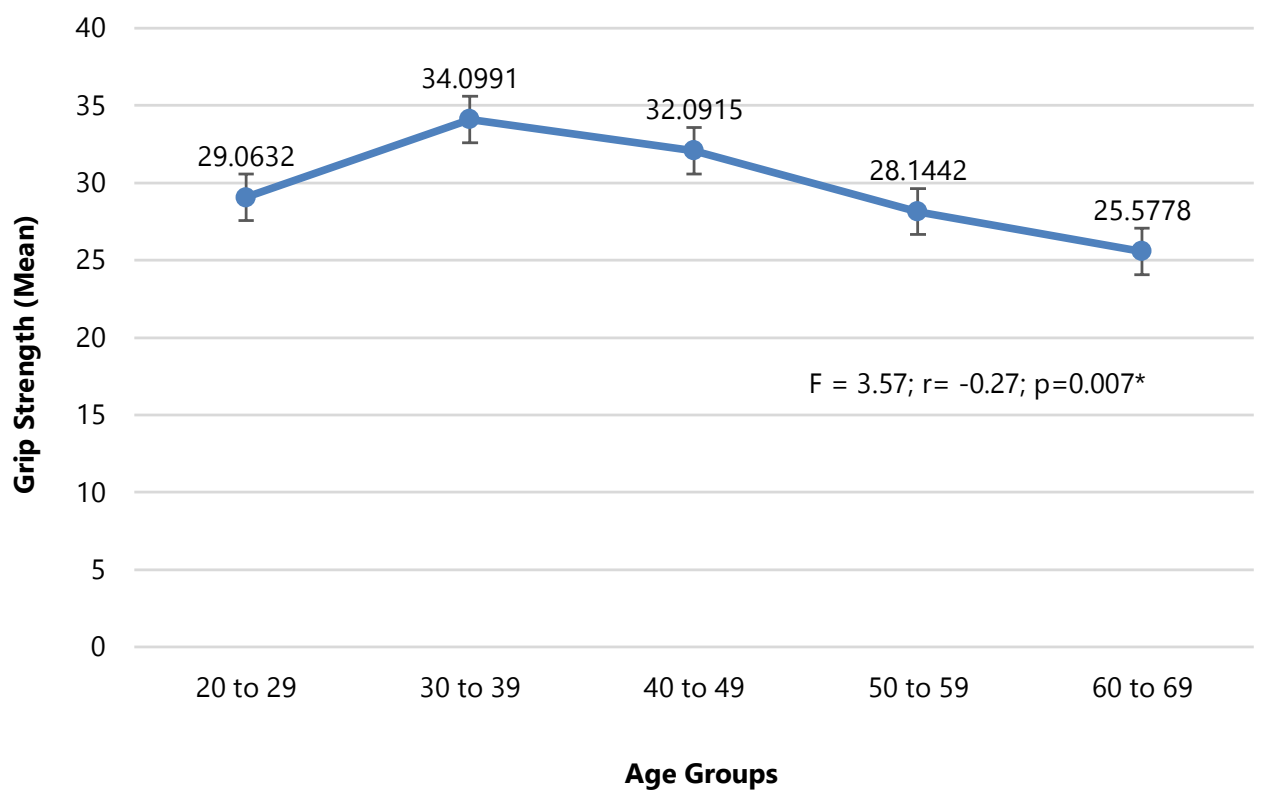

Figure 1: Shows the age-wise decline in the association of grip strength among the study subjects

Table 2: Age-wise correlates of hand-grip strength

\begin{tabular}{lccc}
\hline Age Groups & Beta coefficient & $\mathbf{9 5 \%} \mathbf{C l}$ & p-value \\
\hline 20 to 29 years & 0.15 & $-0.08,1.69$ & 0.076 \\
\hline 30 to 39 years & 0.03 & $-0.72,1.06$ & 0.706 \\
\hline 40 to 49 years & -0.22 & $-1.14,-0.08$ & $0.024^{*}$ \\
\hline 50 to 59 years & -0.20 & $-0.47,-0.01$ & $0.043^{*}$ \\
\hline 60 to 69 years & -0.32 & $-0.42,-0.10$ & $0.001^{*}$ \\
${ }^{*} \mathrm{Cl}=$ confidence interval & & \\
${ }^{*} \mathrm{p}<0.05$ is considered statistically significant &
\end{tabular}

It was noted that there was a linear rise in cortisol level among subjects as age increased. In age group 20 29 mean Cortisol level was found to be $20.14 \pm 3.78$ compared to $20.83 \pm 4.81$ in age group $60-69$ as shown in Figure 2. 


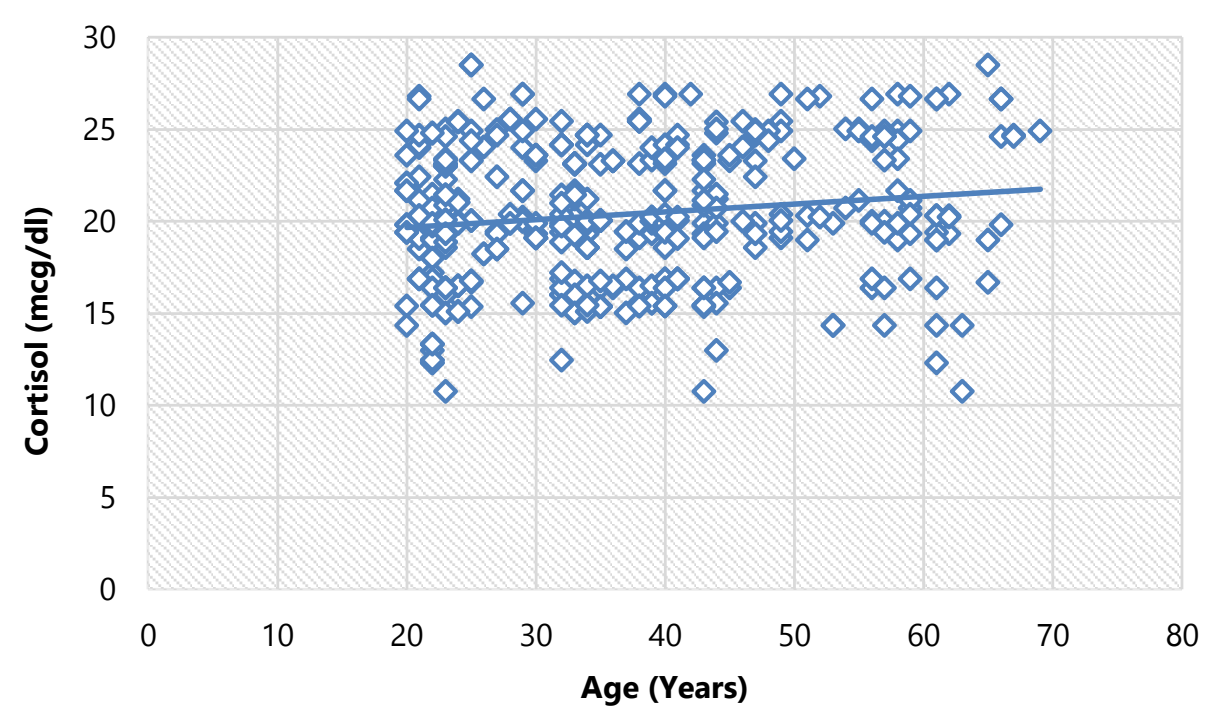

Figure 2: Shows the age-wise rise in cortisol among the study subjects

A significant relationship was found between obesity and cortisol.

Table 3: Comparison of Obesity \& Cortisol $(n=412)$

\begin{tabular}{lcccc}
\hline \multirow{2}{*}{ Obesity } & \multicolumn{3}{c}{ Cortisol Levels } & p-value \\
\cline { 2 - 4 } & Low & Normal & High & \\
\hline Underweight & 3 & 78 & 0 & \multirow{2}{*}{$0.045^{\star}$} \\
\hline Normal & 8 & 216 & 15 & \\
Overweight & 0 & 84 & 8 & \\
\cline { 1 - 4 } & &
\end{tabular}

${ }^{*} p<0.05$ is considered statistically significant

\section{Discussion}

Physical fitness is an important parameter for a healthy life, which is generally lost in old age, especially the loss of muscle strength ${ }^{1,2}$. A useful way to estimate physical fitness and physical wellbeing is the determination of grip strength, which is increasingly used as an indicator of overall muscle strength and function ${ }^{3,4}$. Increased chances of demolished muscle strength up to two times have been observed with elevated cortisol concentrations ${ }^{15}$. And it is a well-established fact that with growing age, grip strength decreases ${ }^{11}$, whereas grip strength is also associated with height and body weight ${ }^{12}$. Thereby, this study was conducted to assess the impact of increased cortisol levels on the grip strength and to determine that the grip strength is the possible indicator for accelerated biological ageing.
A total of 412 subjects were enrolled, and of them, 239 were males \& 173 were females with a mean age of $29.84 \pm 11.550$ years. Of these, the cortisol levels of only 100 participants were assessed, and it was found that 59 subjects with normal cortisol levels had weak grip strength while only 5 with high cortisol $(p=0.000)$. This is due to the fact that muscles might enhance their volume and along with the bluntness in the production of protein through the vast action of cortisol ${ }^{13}$. Moreover, fluctuations in the volume of the muscles in the elderly have been related to the standard level of cortisol. However, chronic stimulation of cortisol has been associated with undesirable outcomes of muscle strength ${ }^{14}$. And could increase the chances of demolished muscle strength up to two times with elevated cortisol concentrations ${ }^{15}$. 
When the association between the grip strength and age was analyzed, it was found that there was a gradual decrease in the grip strength with increasing age. The mean grip strength among the age group of 20 to 29 years was 31.26, while 25.3 among those of 60 to 69 years of age. This is in agreement with other studies. Several studies have shown that poor grip strength predicts increased all-cause mortality in older people $5,17-21$. The underlying mechanisms are poorly understood. Furthermore, muscle strength is known to decline with age, accompanied by a loss of muscle mass and an increase in fat ${ }^{22,23}$.

Moreover, it was also found that the Body Mass Index (BMI), an indicator of obesity was also significantly associated with grip strength $(p=0.039)$. This is due to the fact that poorer grip strength has been associated with higher fasting insulin levels, both cross-sectionally and longitudinally, it seems likely that muscle weakness may precede the development of insulin resistance 24,25 . Some evidence exists that poor strength precedes the development of insulin resistance and predicts diabetes ${ }^{24}$.

Furthermore, it was also found that females were more likely to have weak muscle strength as compared to males $(p=0.001)$. This finding is also similar to the previous researches. The investigators have found a sex difference in grip strength; men have more powerful handgrips than women $^{11,26,27}$.

Research findings in a population of healthy men also determine that grip strength measured in middle age predicts long-term risk of death suggest that influences affecting muscle size and function earlier in life may be important ${ }^{28}$. Our findings are in agreement with this research as the mean Grip strength of the overall population was $31.39 \pm 12.10$, i.e. 109 subjects had weak muscle strength, 191 had normal \& only eight subjects had strong muscle strength. It was observed that most of the subjects from either age groups had weak grip strength, $70.6 \%$ of 20 to 29 years subjects had weak muscle strength, and there was a positive association between the two variables $(p<0.001)$.
Although there is a varying trend in the significance values, but mostly the subjects had either normal or weak muscle strength.

Thus, middle-aged people, poor muscle strength has been found to be associated with lower body weight ${ }^{29}$, presence of chronic diseases ${ }^{30}$, and physical inactivity ${ }^{31}$. In addition, mid-life strength may be modified by earlier lifestyle characteristics, such as exercise habits; other factors such as type of work; or early life diseases that have been cured but have had a negative effect on strength ${ }^{31,32}$. Some evidence exists that poor strength precedes the development of insulin resistance and predicts diabetes $^{24}$. Thereby, good muscle strength has been found to protect older people from disability, independent of chronic diseases ${ }^{31}$. And strong grip strength is associated with physical activity, which in itself predicts better survival ${ }^{33}$.

A greater abdominal fat have been linked with hyper responsiveness towards HPA axis in most studies, however few studies have shown un responsiveness for the same ${ }^{34}$. The current study showed a significant relationship between Obesity and Cortisol level with $p$ value being 0.04 . In women there is an impaired metabolism of cortisol from $5 \beta$ reductase enzyme while in men there is an increased conversion of cortisone to cortisol by $11 \beta$ reductase, that leads to impaired cortisol clearance in obese individuals, which possibly explains the over activation of HPA axis in relation to obesity ${ }^{35}$, although the mechanism involved stays unclear ${ }^{36}$.

\section{Conclusion}

Thus, it was concluded that as the grip strength was decreasing with an increase in obesity, thereby, obese individuals have increased chances of accelerated biological ageing, and weak grip strength and high cortisol baseline levels are an indicator of it. However, future studies are recommended to be conducted on the factors that lead to reduced grip strength and increased cortisol in obese individuals and its relation to chronic disease patients. Additionally, grip strength and cortisol levels could also be assessed in association with the body fat 
representation more deeply for the mutual interconnection of variables related to anthropometry.

\section{Conflicts of Interest}

The authors declare that there is no conflict of interest regarding the publication of this study.

\section{Acknowledgement}

The Author(s) are thankful to Shamoon Noushad and Yusra Saleem for their technical support and cooperation.

\section{Funding}

None.

\section{References}

1. Leveille SG, Bean J, Bandeen - Roche K, Jones $\mathrm{R}_{,}$ Hochberg M, Guralnik JM. Musculoskeletal pain and risk for falls in older disabled women living in the community. J Am Geriatr Soc. 2002;50(4):671678.

2. Iannuzzi-Sucich $M$, Prestwood KM, Kenny AM. Prevalence of sarcopenia and predictors of skeletal muscle mass in healthy, older men and women. J Gerontol A Biol Sci Med Sci. 2002;57(12):M772M777.

3. Cesari M, Fielding RA, Pahor M, Goodpaster B, Hellerstein M, Van Kan GA, Anker SD, Rutkove S, Vrijbloed JW, Isaac M, Rolland Y. Biomarkers of sarcopenia in clinical trials-recommendations from the International Working Group on Sarcopenia. J Cachexia Sarcopeni. 2012;3(3):181190.

4. Sayer AA, Syddall HE, Martin HJ, Dennison EM, Roberts $\mathrm{HC}$, Cooper $\mathrm{C}$. Is grip strength associated with health-related quality of life? Findings from the Hertfordshire Cohort Study. Age Ageing 2006;35(4):409-415.

5. Rantanen $T$, Volpato $S$, Luigi Ferrucci $M$, Eino Heikkinen M, Fried LP, Guralnik JM. Handgrip strength and cause - specific and total mortality in older disabled women: exploring the mechanism. J Am Geriatr Soc. 2003;51(5):636-641.

6. Newman AB, Kupelian V, Visser $M$, Simonsick EM, Goodpaster BH, Kritchevsky SB, Tylavsky FA, Rubin SM, Harris TB. Strength, but not muscle mass, is associated with mortality in the health, aging and body composition study cohort. J Gerontol A Biol Sci Med Sci. 2006:61(1):72-77.

7. Syddall H, Cooper C, Martin F, BRIGGS R, Sayer A. Is grip strength a useful single marker of frailty? Age and Ageing. 2003;32(6):650-656

8. Fried LP, Tangen $C M$, Walston J, Newman $A B$, Hirsch C, Gottdiener J, Seeman T, Tracy R, Kop WJ, Burke G, McBurnie MA. . Frailty in older adults: evidence for a phenotype. J Gerontol A Biol Sci Med Sci. 2001;56(3):M146-M157.

9. Herndon LA, Schmeissner PJ, Dudaronek JM, Brown PA, Listner KM, Sakano Y, Paupard MC, Hall $\mathrm{DH}$, Driscoll M. Stochastic and genetic factors influence tissue-specific decline in ageing $\mathrm{C}$. elegans. Nature. 2002;419(6909):808-814.

10. Korbonits $M$, Trainer PJ, Nelson ML, Howse I, Kopelman PG, Besser GM, Grossman AB, Svec F. Differential stimulation of corticol and dehydropiandrosterone levels by food in obese and normal subjects: relation to body fat distribution. Clin Endocrinol. 1996;45(6):699-706.

11. Kellor M. Hand strength and dexterity. Am J Occup Ther. 1971;25:77-83.

12. Petrofsky JS, Lind AR. Isometric strength, endurance, and the blood pressure and heart rate responses during isometric exercise in healthy men and women, with special reference to age and body fat content. Pflüg Arch. 1975;360(1):49-61.

13. Pauli JR, Souza L, Rogatto G, Gomes R, Luciano E. Glucocorticoids and metabolic syndrome: favorable aspects of physical exercise in this pathophysiology. Portug J Sport Sci. 2006;6(2):217228.

14. Horber F, Scheidegger J, Grünig B, Frey F. Thigh muscle mass and function in patients treated with glucocorticoids. Eur J Clin Invest. 1985;15(6):302307.

15. Peeters G, Van Schoor N, Van Rossum E, Visser M, Lips $P$. The relationship between cortisol, muscle mass and muscle strength in older persons and the role of genetic variations in the glucocorticoid receptor. Clin Endocrinol. 2008;69(4):673-682.

16. Bergendahl M, Iranmanesh A, Mulligan T, Veldhuis JD. Impact of age on cortisol secretory dynamics basally and as driven by nutrient-withdrawal stress. J Clin Endocrinol Metab. 2000;85(6):2203-2214.

17. Division UNP, Economic Do, Affairs S. Population Ageing and Development: 2012. United Nations; 2012.

18. Louie GH, Ward MM. Sex disparities in self reported physical functioning: true differences, reporting bias, or incomplete adjustment for confounding? J Am Geriatr Soc. 2010;58(6):11171122 
19. Al Snih S, Markides KS, Ray L, Ostir GV, Goodwin JS. Handgrip strength and mortality in older Mexican Americans. J Am Geriatr Soc. 2002;50(7):1250-1256.

20. Bassey E, Harries U. Normal values for handgrip strength in 920 men and women aged over 65 years, and longitudinal changes over 4 years in 620 survivors. Clin Sci. 1993;84(3):331-337.

21. Rantanen T, Guralnik JM, Foley D, Masaki K, Leveille $\mathrm{S}$, Curb JD, White L. Midlife hand grip strength as a predictor of old age disability. JAMA. 1999;281(6):558-560.

22. Rantanen T, Harris T, Leveille SG, Visser M, Foley D, Masaki K, Guralnik JM. Muscle strength and body mass index as long-term predictors of mortality in initially healthy men. J Gerontol A Biol Sci Med Sci. 2000;55(3):M168-M173.

23. Beaufrere $B$, Morio B. Fat and protein redistribution with aging: metabolic considerations. European journal of clinical nutrition. 2000;54(3):S48-S53.

24. Lazarus R, Sparrow D, Weiss ST. Handgrip strength and insulin levels: cross-sectional and prospective associations in the Normative Aging Study. Metab. 1997;46(11):1266-1269.

25. Sayer AA, Dennison EM, Syddall HE, Gilbody HJ, Phillips DI, Cooper C. Type 2 diabetes, muscle strength, and impaired physical function: the tip of the iceberg? Diabetes care. 2005;28(10):2541-2542.

26. Kjerland R. Age and sex differences in performance in motility and strength tests. Proc lowa Acad Sci. 1953;60(1):519-523.

27. Anderson W, Cowan N. Hand grip pressure in older people. Br J Prev Soc Med. 1966;20(3):141.

28. Reid KF, Fielding RA. Skeletal muscle power: a critical determinant of physical functioning in older adults. Exerc Sport Sci Rev. 2012;40(1):4.

29. Rantanen T, Masaki K, Foley D, Izmirlian G, White L, Guralnik J. Grip strength changes over $27 \mathrm{yr}$ in Japanese-American men. J App Physiol. 1998;85(6):2047-2053.

30. Bernard S, LeBlanc P, Whittom F, Carrier G, Jobin J, Belleau $R$, Maltais F. Peripheral muscle weakness in patients with chronic obstructive pulmonary disease. Am J Respir Crit Care Med. 1998;158(2):629-634.

31. Rantanen T, Parkatti T, Heikkinen E. Muscle strength according to level of physical exercise and educational background in middle-aged women in Finland. Eur J App Physiol Occup Physiol. 1992;65(6):507-512.

32. Hovi L, Era P, Rautonen J, Siimes MA. Impaired muscle strength in female adolescents and young adults surviving leukemia in childhood. Cancer. 1993;72(1):276-281.
33. Kujala UM, Kaprio J, Sarna S, Koskenvuo M Relationship of leisure-time physical activity and mortality: the Finnish twin cohort. JAMA. 1998;279(6):440-444.

34. Rodriguez AC, Epel ES, White ML, Standen EC, Seckl JR, Tomiyama AJ. Hypothalamic-pituitary-adrenal axis dysregulation and cortisol activity in obesity: a systematic review. Psychoneuroendocrinology. 2015;62:301-318.

35. Andrew R, Phillips DI, Walker BR. Obesity and gender influence cortisol secretion and metabolism in man. The Journal of Clinical Endocrinology \& Metabolism. 1998;83(5):1806.

36. Björntorp P, Rosmond R. Obesity and cortisol. Nutrition. 2000;16(10):924-936. 